Prepared for the U.S. Department of Energy

under Contract DE-AC05-76RL01830

\title{
Majorana Electroformed Copper Mechanical Analysis
}
NR Overman
DJ Edwards
CT Overman
EW Hoppe
TA Kafentzis

April 2012

Pacific Northwest

NATIONAL LABORATORY

Proudly Operated by Battelle Since 1965 


\title{
DISCLAIMER
}

This report was prepared as an account of work sponsored by an agency of the United States Government. Neither the United States Government nor any agency thereof, nor Battelle Memorial Institute, nor any of their employees, makes any warranty, express or implied, or assumes any legal liability or responsibility for the accuracy, completeness, or usefulness of any information, apparatus, product, or process disclosed, or represents that its use would not infringe privately owned rights. Reference herein to any specific commercial product, process, or service by trade name, trademark, manufacturer, or otherwise does not necessarily constitute or imply its endorsement, recommendation, or favoring by the United States Government or any agency thereof, or Battelle Memorial Institute. The views and opinions of authors expressed herein do not necessarily state or reflect those of the United States Government or any agency thereof.

\author{
PACIFIC NORTHWEST NATIONAL LABORATORY \\ operated by \\ BATTELLE \\ for the \\ UNITED STATES DEPARTMENT OF ENERGY \\ under Contract DE-AC05-76RL01830
}

Printed in the United States of America
Available to DOE and DOE contractors from the Office of Scientific and Technical Information,
P.O. Box 62, Oak Ridge, TN 37831-0062;
ph: (865) 576-8401
fax: $(865)$ 576-5728
email: reports@adonis.osti.gov

\begin{abstract}
Available to the public from the National Technical Information Service, U.S. Department of Commerce, 5285 Port Royal Rd., Springfield, VA 22161 ph: (800) 553-6847 fax: $(703) 605-6900$ email: orders@ntis.fedworld.gov online ordering: http://www.ntis.gov/ordering.htm
\end{abstract}

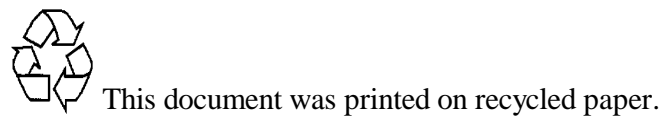


PNNL-21315

\title{
Majorana Electroformed Copper Mechanical Analysis
}

\author{
NR Overman DJ Edwards \\ CT Overman EW Hoppe \\ TA Kafentzis
}

April 2012

Prepared for the U.S. Department of Energy under Contract DE-AC05-76RL01830

Pacific Northwest National Laboratory

Richland, Washington 99352 


\section{Executive Summary}

The MAJORANA DEMONSTRATOR is a large array of ultra-low background high-purity germanium detectors, enriched in ${ }^{76} \mathrm{Ge}$, designed to search for zero-neutrino double-beta decay (0v $\left.\beta \beta\right)$. The DEMONSTRATOR will utilize ultra high purity electroformed copper for a variety of detector components and shielding.

A preliminary mechanical evaluation was performed on the Majorana prototype electroformed copper material. Several samples were removed from a variety of positions on the mandrel. Tensile testing, optical metallography, scanning electron microscopy, and hardness testing were conducted to evaluate mechanical response. Analyses carried out on the Majorana prototype copper to this point show consistent mechanical response from a variety of test locations. Evaluation shows the copper meets or exceeds the design specifications.

Some evidence of potential anisotropic material response has been identified. The effect is most noticeable at high strains and further research will be required to complete the characterization. 


\section{Acronyms and Abbreviations}

$\begin{array}{ll}\text { FESEM } & \text { Field Emission Scanning Electron Microscope } \\ \text { EBSD } & \text { Electron Backscatter Diffraction } \\ \text { OIM } & \text { Orientation Imaging Microscopy } \\ \text { HV } & \text { Vickers Hardness } \\ \text { HK } & \text { Knoop Hardness } \\ \text { QA } & \text { Quality Assurance } \\ \text { E } & \text { Young's Modulus } \\ \text { GD } & \text { Growth Direction } \\ \text { CTE } & \text { Coefficient of Thermal Expansion } \\ \text { OFHC } & \text { Oxygen Free High Conductivity } \\ \text { SUL } & \text { Sanford Underground Lab } \\ \text { TCR } & \text { Temporary Clean Room } \\ \text { gf } & \text { Gram-Force }\end{array}$




\section{Contents}

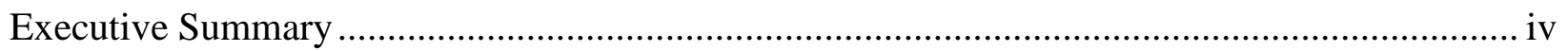

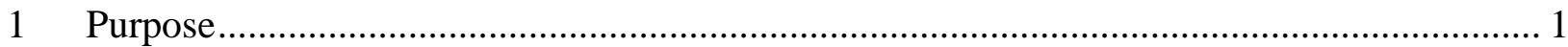

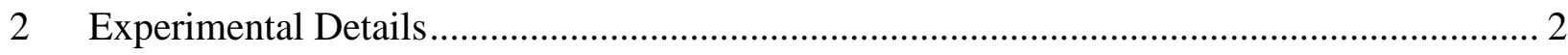

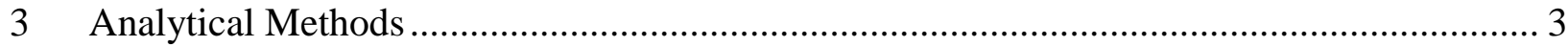

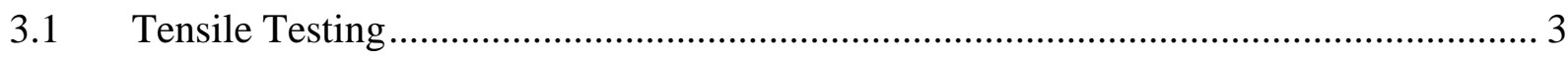

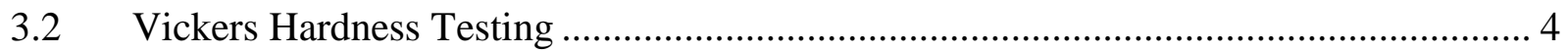

3.3 Fracture Analysis \& Microstructural Evaluation ................................................... 7

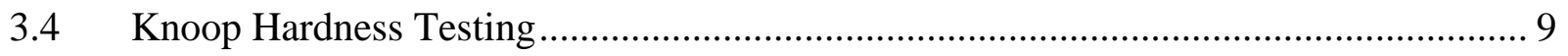

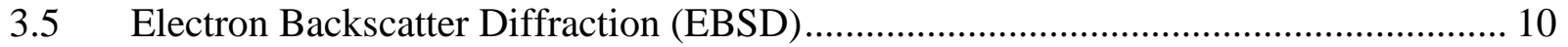

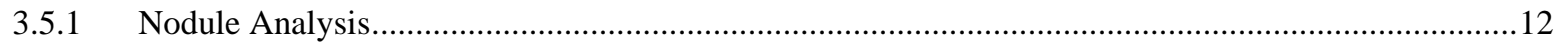

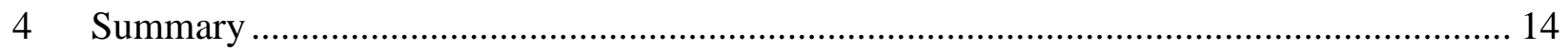

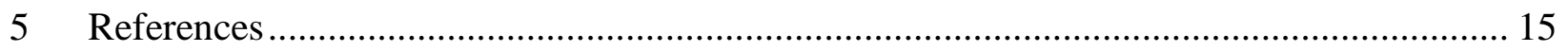

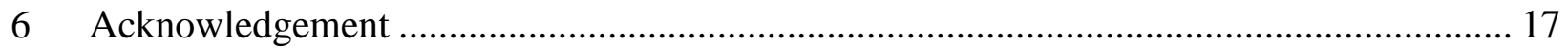




\section{Figures and Tables}

\section{Figures:}

Figure 2.1 A) Mandrel diagram which depicts sampling regions. B) Magnified image of sampling location with green highlighted regions indicating test plane orientation.

Figure 3.1 Left) Stress vs. strain plots for eight samples from varying locations on the mandrel. Right) Magnified image of the linear elastic region showing the yield point evaluation. As shown in the legend, sample position as described in Figure 2.1, T) Top, M) Middle or B) bottom is given, followed by the sample number performed in that region. 3

Figure 3.2 Hardness contour maps (samples B1and B2) generated by LECO AMH-43 automated hardness tester.

Figure 3.3 Left) Variance in Hardness through deposit thickness of two samples grown from the bottom of the mandrel. Right) Normal distribution of hardness. 5

Figure 3.4 Uniformity of hardness in circumferential direction. ......................................... 6

Figure 3.5 Fracture surface of failed tensile specimen with GD indicating growth direction...... 7

Figure 3.6 Aligned grain structure of electroformed copper. .............................................. 8

Figure 3.7 Angled Knoop indentation testing........................................................... 9

Figure 3.8 Hardness results of angled Knoop indentation testing. ....................................... 9

Figure 3.9 EBSD analysis of thin electroformed copper sample. Growth direction shown as GD. 10

Figure 3.10 EBSD analysis of prototype copper perpendicular to growth front. ..................... 11

Figure 3.11 Pole Figures from EBSD analysis of prototype copper with test plane perpendicular to growth front. Mandrel Axis (MA) Circumferential Direction (CD) ............................ 11

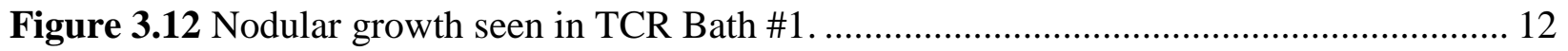

Figure 3.13 EBSD performed on nodular growth from thin electroplate. ............................... 13

Tables:

Table 3.1 Mechanical Properties Results Thick Electrodeposited Copper ................................ 4

Table 3.2 Hardnesss Results Thick Electrodeposited Copper............................................... 6 


\section{Purpose}

High purity materials are needed for the construction of ultra-low level radiation detectors. ${ }^{5,9}$ These detectors are used for environmental research as well as rare nuclear decay experiments, e.g. probing the effective mass and character of the neutrino. ${ }^{3}$ The Majorana Demonstrator project is a collaborational research effort focused on the measurement and identification of the mass of the electron neutrino. ${ }^{5}$ This will be accomplished by the observation of neutrinoless double beta decay in $76 \mathrm{Ge}$. Due to the rarity of this decay mode, background radiation will have to be essentially zero in order to accurately detect and identify the few events that may occur within an experimenter's lifetime. To accommodate such stringent background requirements a deep underground location and specialty materials of high radiopurity are essential.

One such material, critical to the success of this experiment is copper. Commercially available high purity copper coupled with further electrochemical purification produces electrodeposited copper of extreme radiopurity $(<0.1 \mu \mathrm{Bq} \mathrm{U} / \mathrm{kg} \mathrm{Cu}){ }^{2}$ Additionally, because of its attractive electrical, thermal and mechanical properties, copper is used for a variety of components in the detector array as well as shielding from background radiation. Electroplating high purity commercial OFHC copper allows for impurities such as thorium and uranium to be removed. This can be attributed to the fact that plating of these elements is not energetically favorable when deposition parameters are constrained to the half cell potential of copper. ${ }^{2}$

Electrodeposition of copper is a technique commonly employed in the microelectronics industry as a purification method, and characterization of these thin electrodeposited films has been readily performed. However, the length scales at which these experiments have been typically performed have not been shown to translate to bulk electroformed material. Majorana electroformed copper is typically deposited on large cylindrical mandrels, 23 inches in length and 13 inches in diameter. The electroformed copper can be as thick as 0.55 inches and can weigh as much as $2001 \mathrm{bs}$. Additionally, electroformed copper deposits tend to exhibit abnormal growth. These effects can be seen both in the microstructure of the plated copper and along edges of the cylindrical cathode where field effects are greatest. Because of the critical role copper plays in this experiment, a detailed chemical and physical properties analysis is required. 


\section{Experimental Details}

For this study, all electroplating was performed in a class 1000 cleanroom at Pacific Northwest National Lab. OFHC copper anode material of $\geq 99.995 \%$ purity was deposited onto a type 316 stainless steel cylindrical cathode. The plating bath was composed of 1.0M Sulfuric Acid and 0.3M Copper Sulfate, although this composition changes over time during the plating process. Custom reverse pulse power supplies obtained from Dynatronix, Inc. were used for deposition of the copper.

After a brief forward current only nucleating period, a pulse/reverse pulse waveform was utilized for its leveling effect on the deposit, and to hinder deposition of contaminant materials via mass transport. Deposition of the copper was performed at $0.34 \mathrm{~V}$ for a continuous eight months to achieve a very thick deposit measured which averaged 0.48 inches.

After deposition on the stainless steel cathode was completed, the entire assembly was put into a furnace at $260^{\circ} \mathrm{C}$ for 4 hours then rapidly quenched in a water bath. While the likelihood for changes in the microstructure during this heating cycle is significant, this technique takes advantage of the CTE mismatch and is necessary for non-destructive removal of copper from the mandrel surface.

Tensile specimens were machined according to ASTM E8/E8M-09 and tested with the use of an Instron MTS 8800 tension tester at room temperature with a strain rate of $0.05 \mathrm{in} / \mathrm{min}$. Samples were machined from three locations on the mandrel, top, middle and bottom to ensure uniform mechanical response throughout the electroplate. An array of hardness measurements were performed through the thickness of the copper workpiece using a LECO AMH43 hardness tester. A JEOL FESEM was used to perform EBSD analyses of the electroformed copper throughout the thickness of the deposit and perpendicular to the growth front. For the purposes of this document, a schematic of an electroplated copper deposit is shown in Figure 2.1 below.

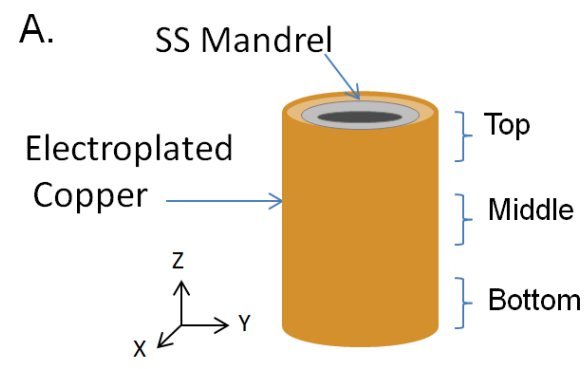

B.

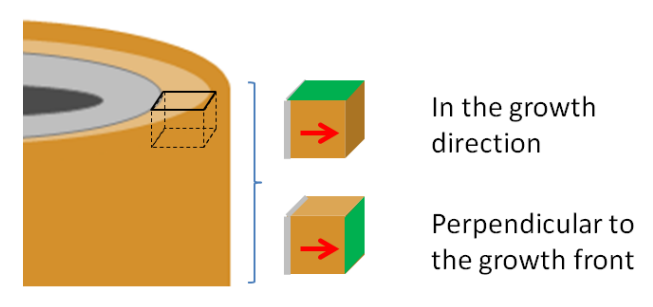

Figure 2.1 A) Mandrel diagram which depicts sampling regions. B) Magnified image of sampling location with green highlighted regions indicating test plane orientation. 


\section{Analytical Methods}

\subsection{Tensile Testing}

Tensile testing allows for properties information to be obtained in a relatively short amount of time under uniaxial tensile stresses. Results of these tests (Figure 3.1) show a high degree of reproducibility indicating uniformity of the electroplated deposit, despite the contribution of field effects which locally increased deposition rates around the bottom edge of the mandrel.
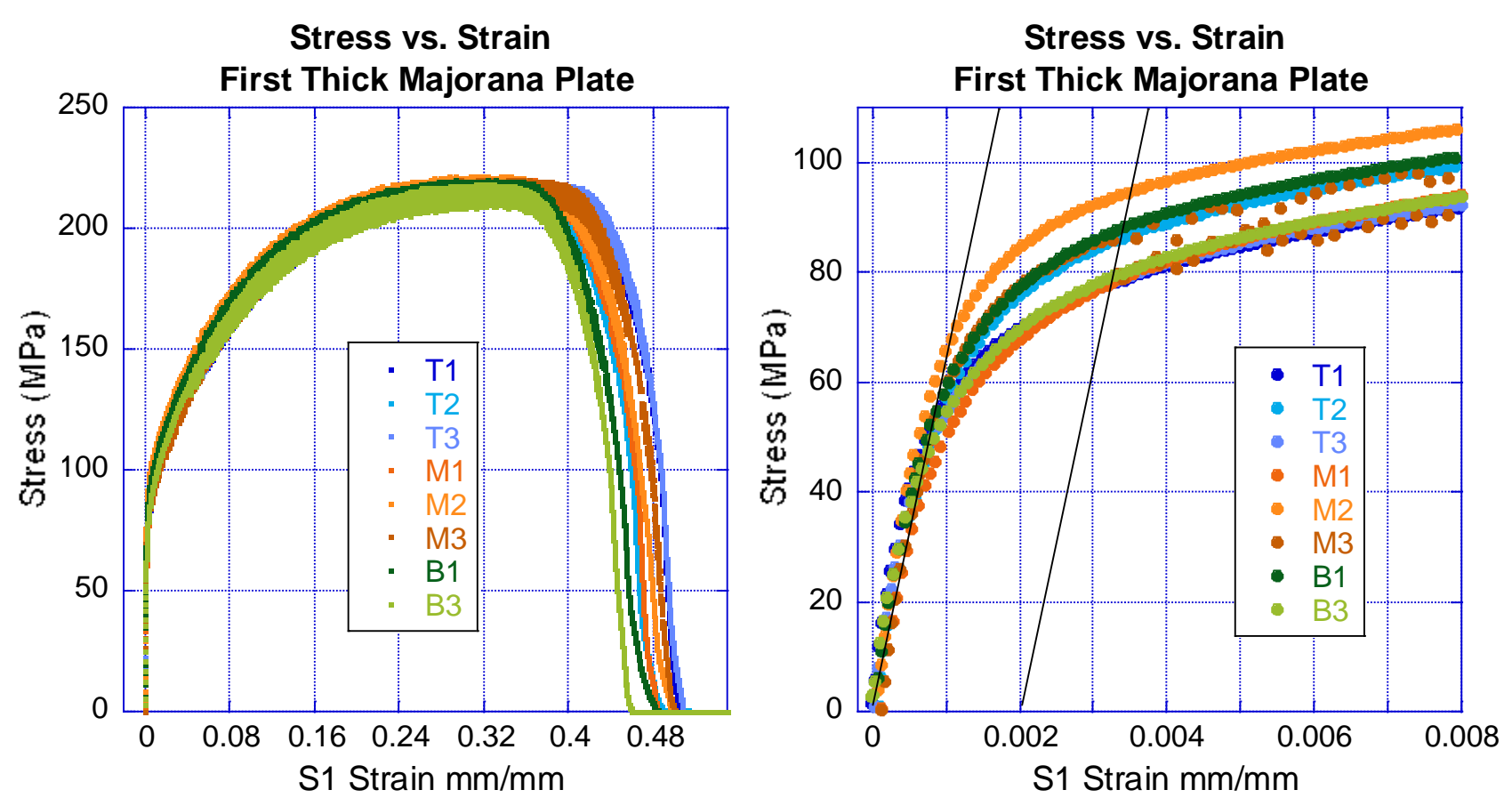

Figure 3.1 Left) Stress vs. strain plots for eight samples from varying locations on the mandrel. Right) Magnified image of the linear elastic region showing the yield point evaluation. As shown in the legend, sample position as described in Figure 2.1, T) Top, M) Middle or B) bottom is given, followed by the sample number performed in that region.

As shown in Figure 3.1 above, the Majorana prototype copper exhibits a high degree of strain hardening before failure, indicated by the slope after the onset of yielding. This aspect alone shows that from an operational standpoint, no catastrophic failure of the copper is likely to occur should the yield point be exceeded during use. While strain hardening is typically seen for FCC materials, this in addition to the clearly defined yield is indicative of a dense electroplate free of significant voids or other structural abnormalities which could otherwise lead to premature failures.

Elastic modulus values were calculated using Hooke's Law and averaged over the eight tests performed. The $0.2 \%$ offset yield strength, ultimate tensile strength and total percent elongation 
are shown in Table 1. The average yield strength across all areas was shown to be $83.2 \mathrm{MPa}$ $(12.1 \mathrm{ksi})$.

Table 3.1 Mechanical Properties Results Thick Electrodeposited Copper

\begin{tabular}{|l|l|l|l|l|}
\hline $\begin{array}{l}\text { Sample } \\
\text { Location }\end{array}$ & $\begin{array}{l}\text { Yield Stress } \\
(\mathrm{MPa})\end{array}$ & $\begin{array}{l}\text { Elastic } \\
\text { Modulus } \\
(\mathrm{GPa})\end{array}$ & $\begin{array}{l}\text { Ultimate Tensile } \\
\text { Strength (MPa) }\end{array}$ & $\begin{array}{l}\text { Percent } \\
\text { Elongation } \\
\text { at Failure }\end{array}$ \\
\hline Top & $80.5 \pm 3.9$ & $75.2 \pm 4.2$ & $215.5 \pm 5$ & 44 \\
\hline Middle & $85.8 \pm 7.8$ & $77.8 \pm 15.6$ & $215.5 \pm 5$ & 44 \\
\hline Bottom & $83.3 \pm 6.0$ & $67.5 \pm 3.2$ & $214 \pm 5$ & 41 \\
\hline
\end{tabular}

While the observed yield stress is lower than that of bulk copper (209 MPa Annealed, $344 \mathrm{MPa}$ Cold Drawn $)^{1}$, the data gathered shows that the Majorana electroformed copper should be able to support the $48.2 \mathrm{MPa}$ (7ksi) design specifications.

Due to the required time and costs associated with machining and testing tensile specimens, a faster and less expensive quality assurance test method was sought out for use on all electroformed copper. Taking into consideration the high value of the electroformed copper, the chosen method would sample smaller volumes of material, resulting in the maximum amount of copper for detector components. Hardness testing is one method used to estimate other mechanical properties information. It is a non-destructive test method which allows large quantities of information to be obtained from very small volumes of material. Through use of the Tabor relation ${ }^{10}$, a correlation between the yield strength and hardness exists and is shown as

$$
H=C * \sigma_{y}
$$

Where $\mathrm{H}$ is the hardness measured in $\mathrm{kg} / \mathrm{mm}^{2}, \mathrm{C}$ is a constant and $\sigma_{\mathrm{y}}$ is the yield stress. The value of $\mathrm{C}$ for this case will be taken as 3. ${ }^{6,10}$ This relation assumes the test material is an isotropic, rigid and perfectly plastic solid. Due to the strains associated with indenter tip geometry, the yield stress in this equation is representative of the yield point at a strain of 7 to 8 percent. 6,10

\subsection{Vickers Hardness Testing}

Vickers hardness testing was first utilized to perform hardness contour maps on samples extracted from the grip ends of the tensile specimens. Samples from regions across the mandrel were tested and mapping was performed to show the variance in hardness throughout a sample. A large variance in hardness would indicate this test method would be unsuitable for future QA testing.

All hardness measurements were performed using a 200gram-force (gf) load. Vickers testing was the preferred method for generation of hardness contour plots because of the symmetric deformation associated with this pyramidal tip geometry, allowing larger sampling arrays to be performed. Hardness contour maps were generated across a $0.35 \mathrm{in}$. diameter surface 
representative of the electroplated thickness and show only slight deviations, Figure 3.2. The testing shown here was performed in a plane parallel to the growth direction.

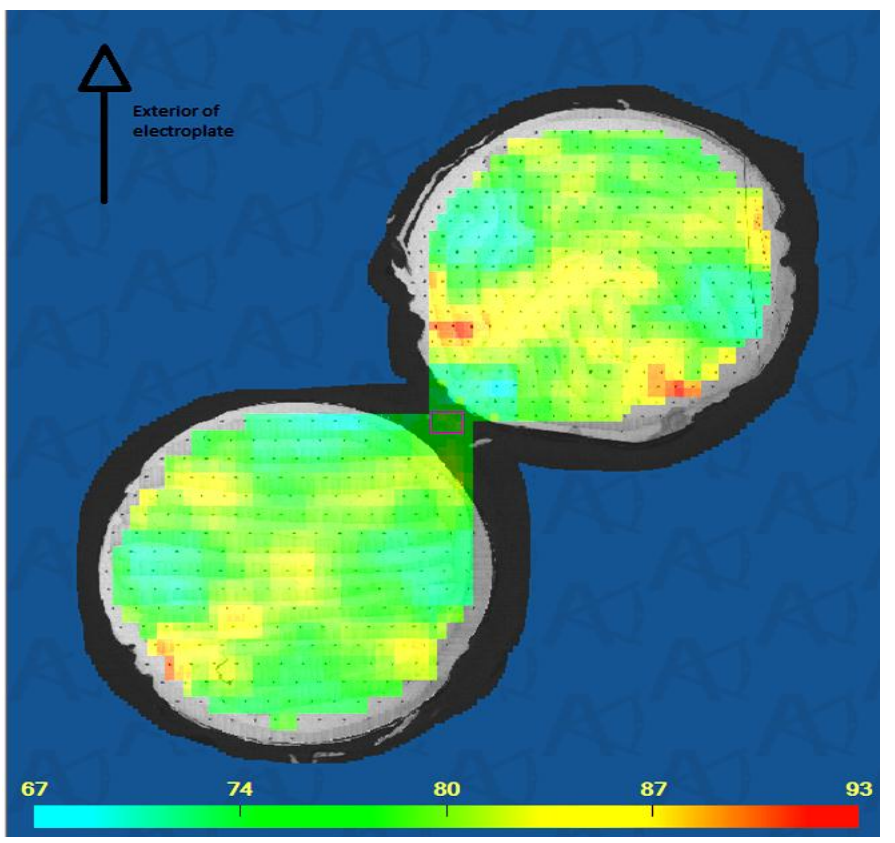

Figure 3.2 Hardness contour maps (samples B1and B2) generated by LECO AMH-43 automated hardness tester.

Figure 3.3 below shows graphical representations of the hardness values obtained from testing.

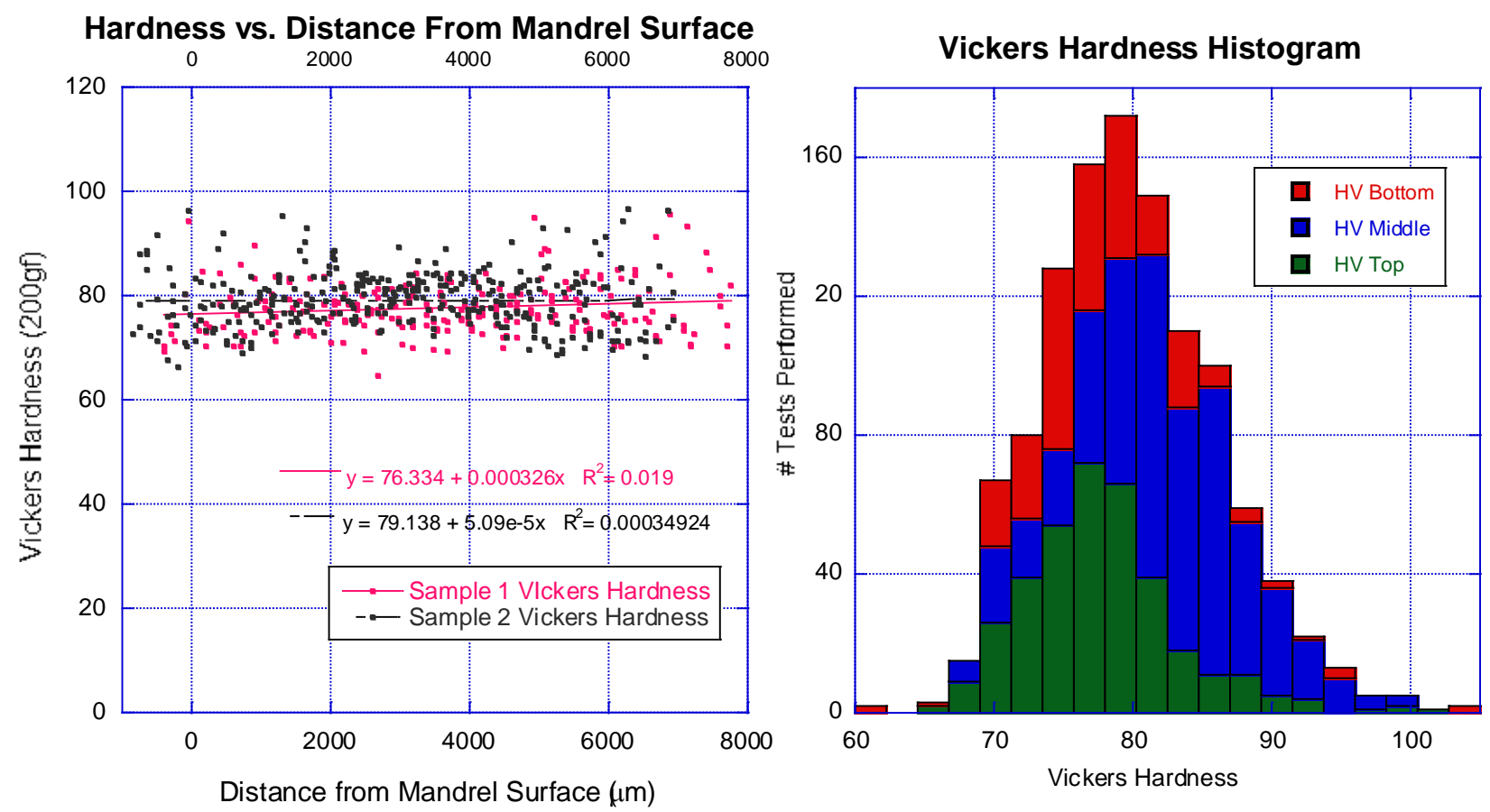

Figure 3.3 Left) Variance in Hardness through deposit thickness of two samples grown from the bottom of the mandrel. Right) Normal distribution of hardness. 
Vickers indentation testing was also performed perpendicular to the growth direction. Hardness measured in both of these planes showed good correlation. Figure 3.4 below shows the hardness variation with respect to distance. In this case, the distance shown is not in the direction of growth, but along the circumferential direction.

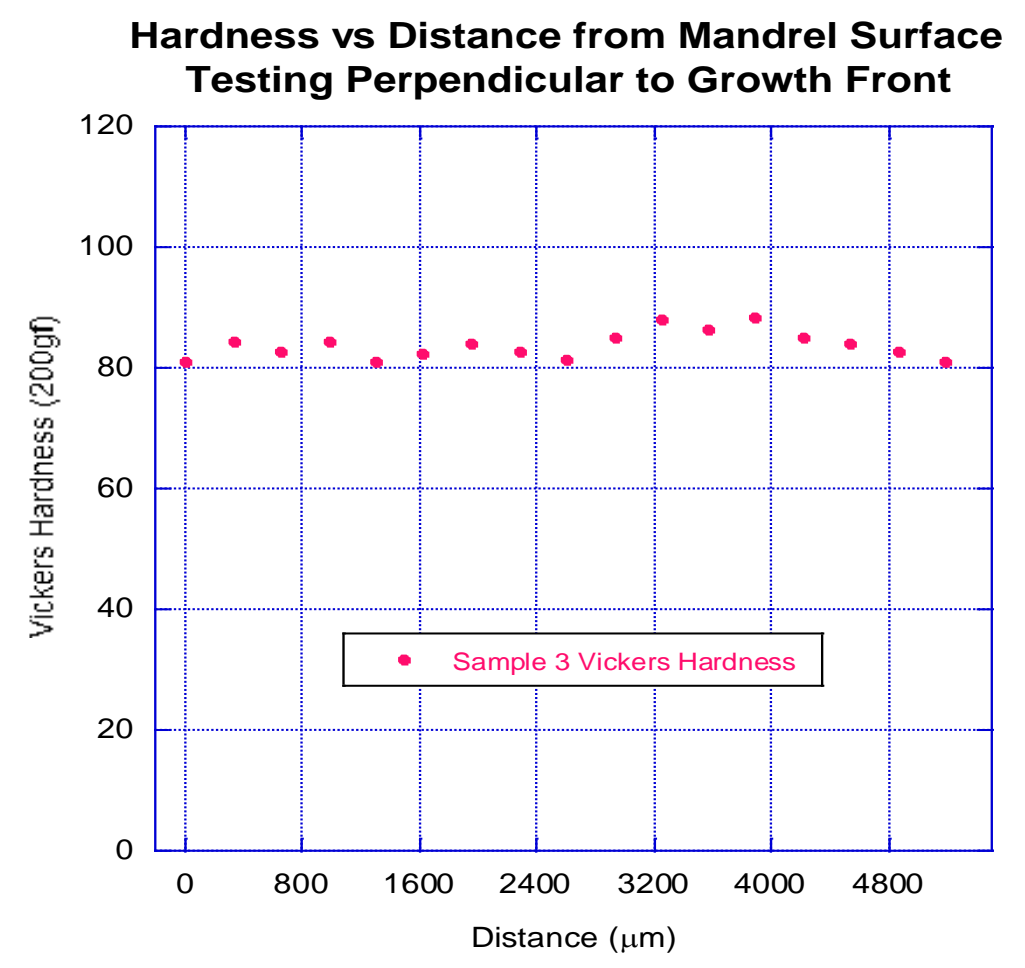

Figure 3.4 Uniformity of hardness in circumferential direction.

Results of hardness testing performed are summarized in Table 2. Because of the consistency of the Vickers data gathered, this method was shown to be a viable option for a fast and reliable QA check on the electroformed copper. Additionally, the hardness was shown to be uniform down the length of the mandrel and on several different test planes (parallel and perpendicular to the growth direction).

Table 3.2 Hardnesss Results Thick Electrodeposited Copper

\begin{tabular}{|l|l|}
\hline $\begin{array}{l}\text { Sample } \\
\text { Location }\end{array}$ & $\begin{array}{l}\text { Hardness (HV) } \\
\text { @ 200 g.f. load }\end{array}$ \\
\hline Top & $77.9 \pm 5.8$ \\
\hline Middle & $82.5 \pm 6.2$ \\
\hline Bottom & $78.4 \pm 5.7$ \\
\hline
\end{tabular}


Using the Tabor relation, as discussed previously the yield strength at 7 to $8 \%$ strain can be estimated from the hardness information obtained. The average hardness over all areas of the copper electroplate was measured $79.8 \pm 5.3 \mathrm{HV}$. Using this value, the estimated yield strength would be $260.5 \pm 17.2 \mathrm{MPa}(37.8 \pm 2.5 \mathrm{ksi})$. Looking back on the tensile data, the actual stress at $7.5 \%$ strain was measured at $165 \mathrm{MPa}$ which does not show the expected correlation. Because this correlation is only valid for isotropic materials with rigid perfectly plastic behavior, some deviation is expected. However, the significant difference shown would suggest some degree of anisotropy exists in the electroformed copper.

\subsection{Fracture Analysis \& Microstructural Evaluation}

Support of the anisotropic properties can be seen through fracture analysis of the tested tensile specimens. Figure 3.5 shows the typical cup and cone fracture surface seen in ductile materials is skewed, deforming non-uniformly in the direction of growth. This fracture surface is typical of the nine specimens tested. Scanning electron microscopy was also used to identify possible preferential texture.

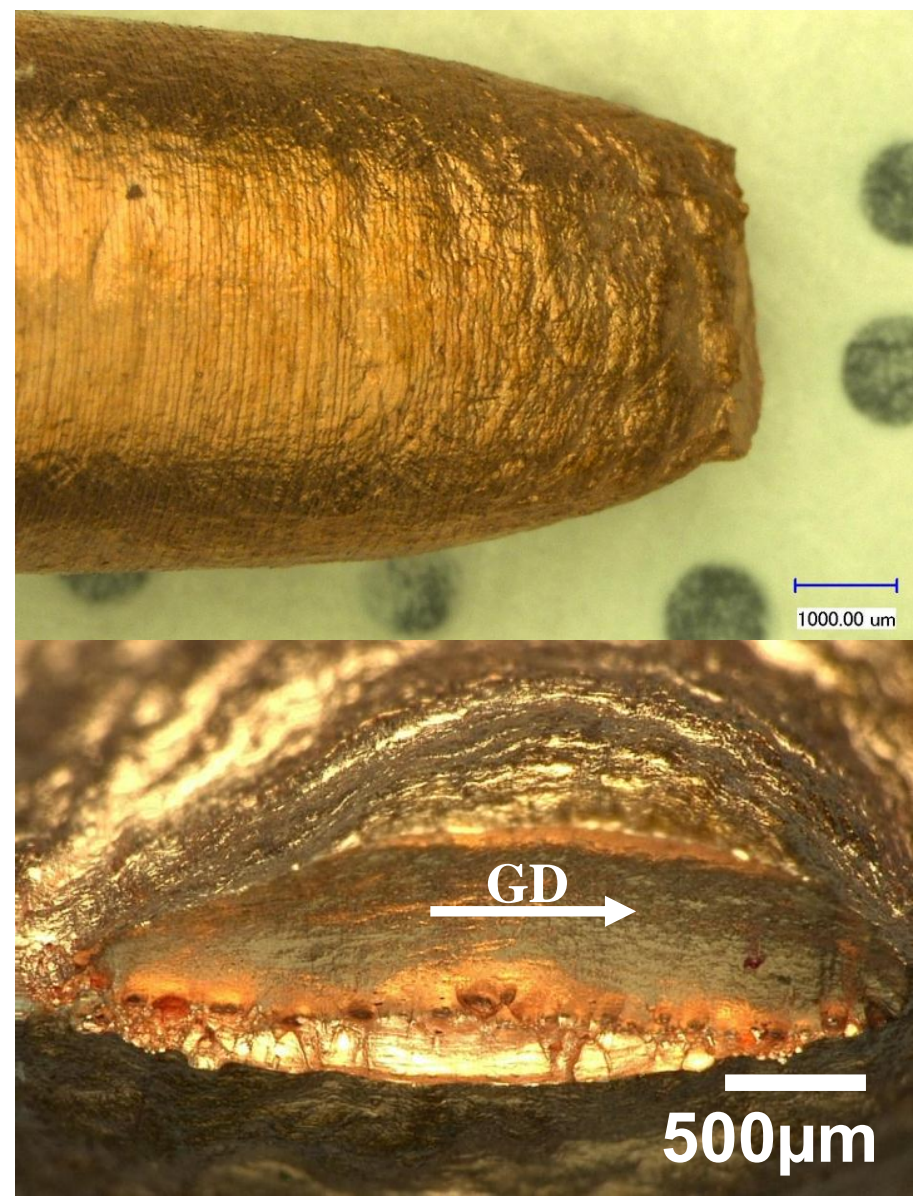

Figure 3.5 Fracture surface of failed tensile specimen with GD indicating growth direction. 
Characterization of the microstructure was performed by first mounting a copper specimen and polishing to a mirror finish using $0.3 \mu \mathrm{m}$ diamond paste. A 1:1:0.3 mixture of DI water, Ammonium Hydroxide and 3\% Hydrogen Peroxide was used to reveal the structure. As shown below, samples taken from one copper electrodeposit exhibit a consistent structure aligned in the direction of growth (GD).

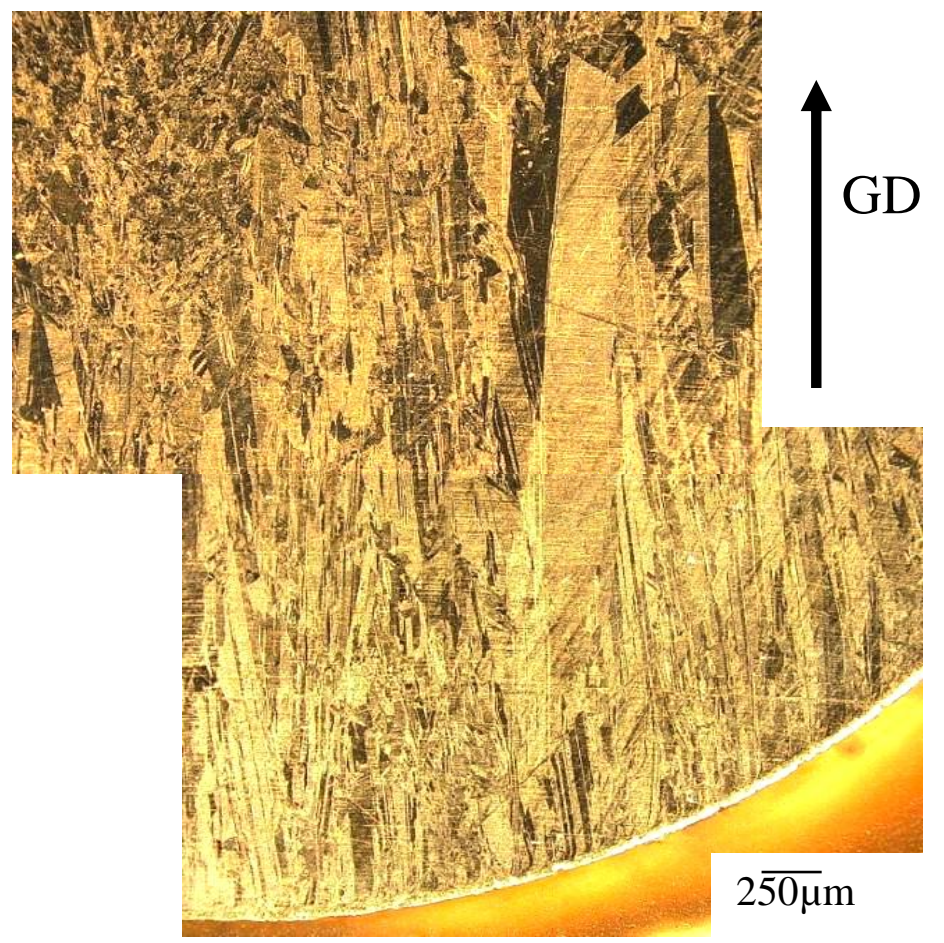

Figure 3.6 Aligned grain structure of electroformed copper.

While the Figure 3.6 depicts elongated grain growth in the direction of deposition, this doesn't require a predominant texture be present, which would result in anisotropic material response. To gain an idea of texture present in the copper, further investigation using the Knoop hardness test method was utilized. This method is particularly useful for identifying anisotropic material response, provided the indenter tip spans multiple grains. The geometry of a Knoop indenter tip is pyramidal with an aspect ratio of 7:1, this allows for directional hardness testing to be performed for the purpose of anisotropic material identification. 


\subsection{Knoop Hardness Testing}

Knoop hardness testing was performed by varying the long axis of the indentation. Initially, testing was performed with the long axis of the indenter tip parallel to the growth direction then successive measurements were taken by stepwise rotation and measurement on the sample. Rotations were performed with step sizes of $15^{\circ}$ to $30^{\circ}$ at a time.

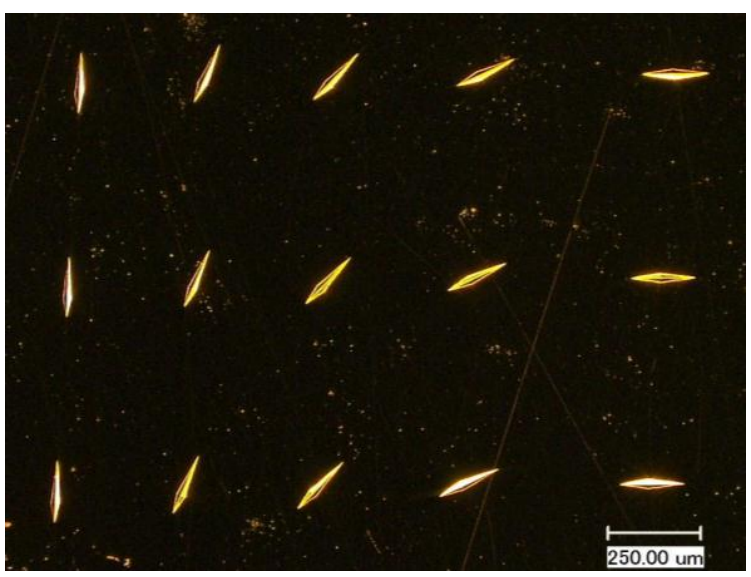

Figure 3.7 Angled Knoop indentation testing.

The hardness information obtained using the Knoop indenter tip was shown to not vary significantly when measurements were recorded in the growth direction, however, slight increases in the deviation values were seen when testing was performed perpendicular to the growth front as shown in Figure 3.8
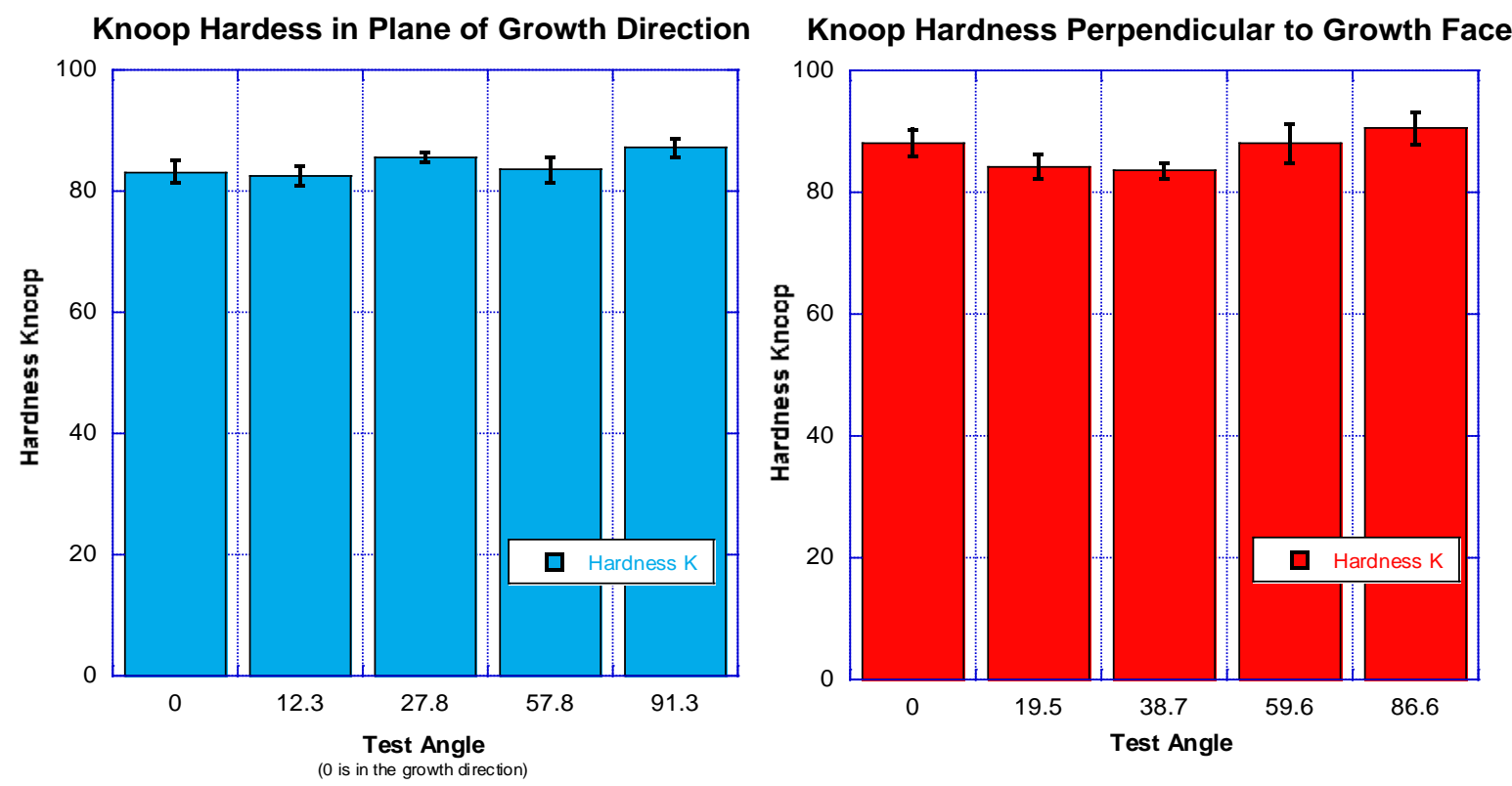

Figure 3.8 Hardness results of angled Knoop indentation testing.

However, due to the subtlety of this effect, no significant correlations were drawn from the results of this testing. 


\subsection{Electron Backscatter Diffraction (EBSD)}

Due to the eleongated fracture surface (Figure 3.5) and the highly aligned microstructure (Figure 3.6) significant evidence was there to support the potential for anisotropic properties of the deposit, despite the fact that it was not observed by knoop indentation testing. EBSD was then utilized in an effort to better understand this. A JEOL 7600 Field Emission Scanning Electron Microscope (FESEM) was used to carry out texture studies on the electrodeposited copper. Previous characterization work has been performed on thin copper electroplates in the growth direction. Results of these studies are included below for comparative purposes. These results (Figure 3.9) show both the variation in grain size with deposit thickness and respective pole figures depicting preferred texture.

\section{$3 \mathrm{~mm}$}
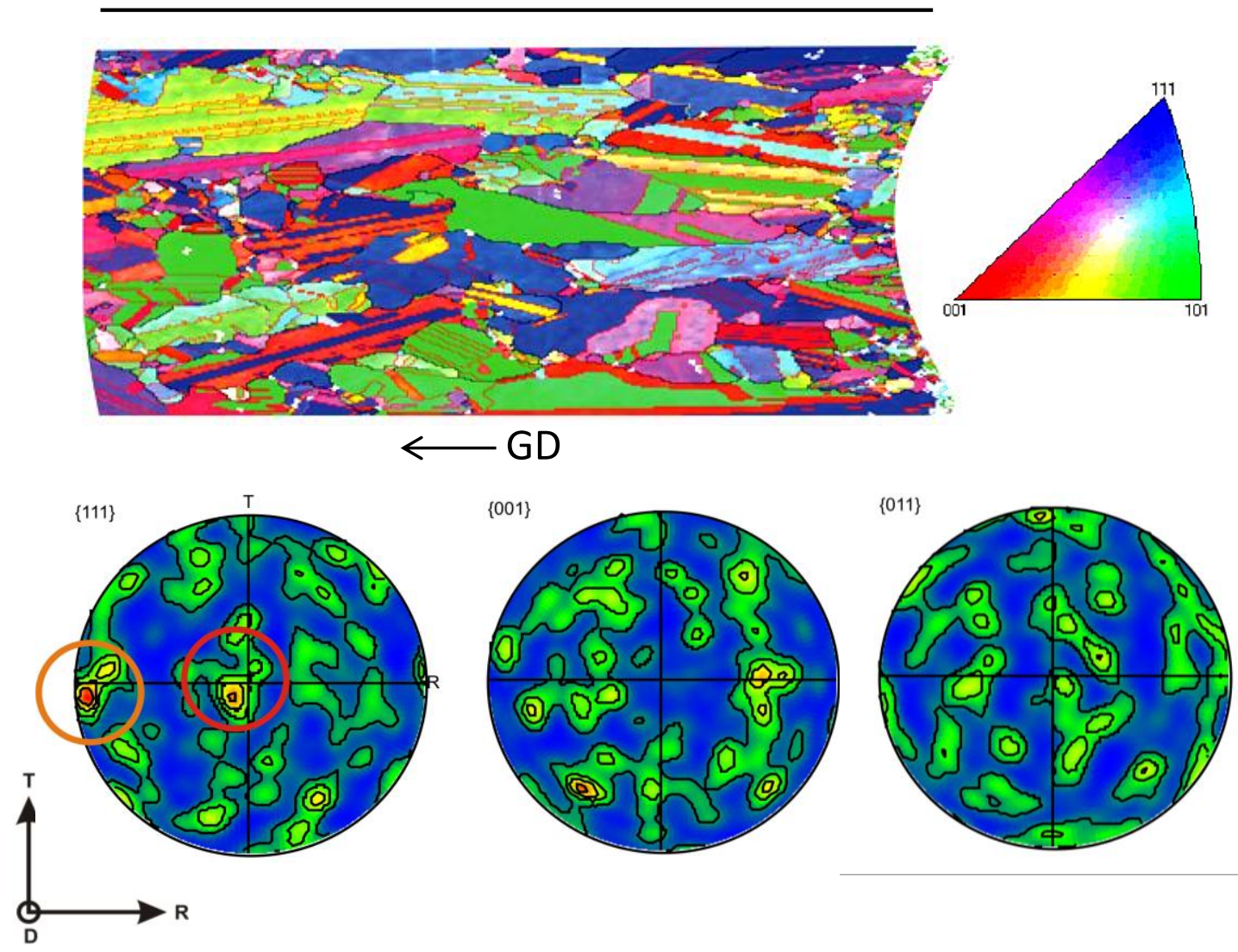

Figure 3.9 EBSD analysis of thin electroformed copper sample. Growth direction shown as GD.

The observed grain structure seen in Figure 3.9 was shown to be elongated in the growth direction, similar to the observed microstructure of the prototype copper. Pole figures of the grain orientations show very minimal clustering about the (111) plane. Since copper is a Face Centered Cubic (FCC) material, heavy alignment of this close packed plane would lead to potential anisotropic effects in mechanical properties. However, due to the high fraction of twinning present and small size of this electroplate in comparison to the prototype copper, 
further analyses was required. Twinning is evidenced in Figure 3.9 by the linear intragranular grain segments which exhibit a distinct misorientation with respect to the surrounding grain.

To this point, EBSD analyses performed on the Majorana prototype copper are limited to those performed perpendicular to the growth front (Figure 2.1). Results from this work are preliminary, as only one sample has been analyzed. Noise reduction and Kuwahara filtering with a two degree smoothing angle were utilized. EBSD has shown Majorana prototype copper continues to exhibit a bimodal grain size distribution. Elongated grains are not present, as anticipated due to the test plane geometry. Clustered fine grain regions exist between the large grains. With limited data on the electroplated material, it is difficult to ascertain if the bimodal grain distribution is the result of a perpendicular test plane geometry, or recrystallization from removal of the copper.

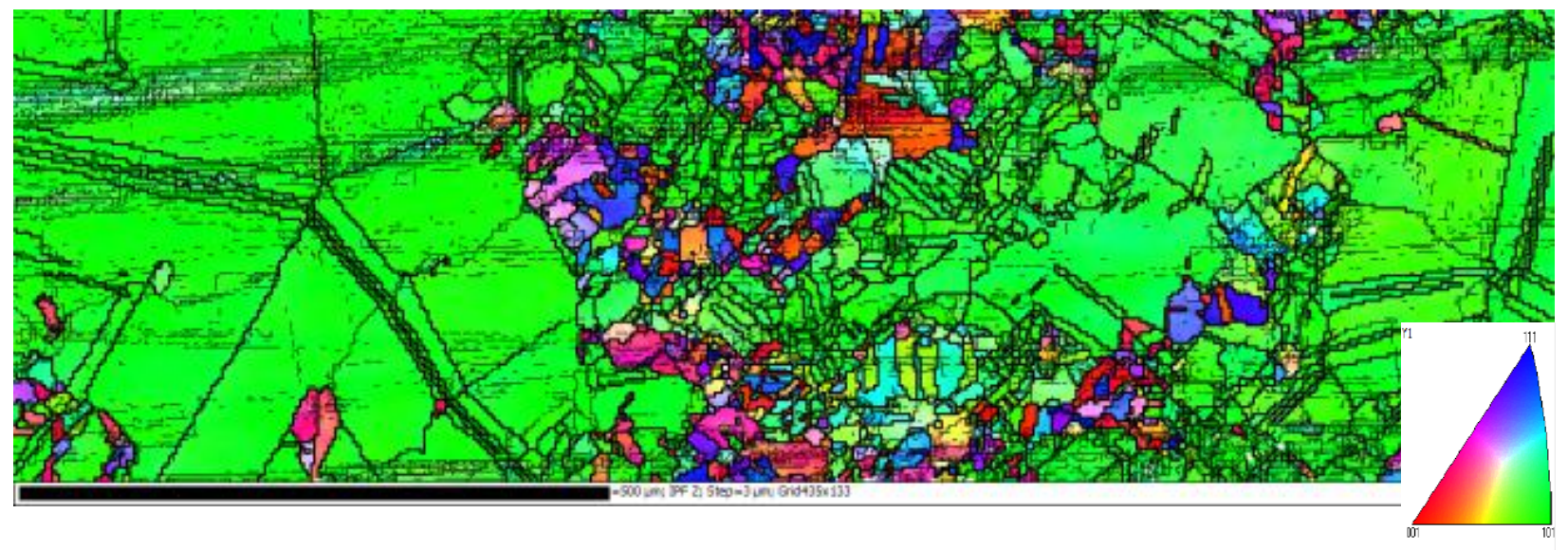

Figure 3.10 EBSD analysis of prototype copper perpendicular to growth front.

Additionally, analysis of the EBSD pattern and pole figures for this sample also showed significant texture clustering as seen in Figure 3.11. Which indicates the development of a $\langle 011\rangle$ fiber texture in the growth direction.
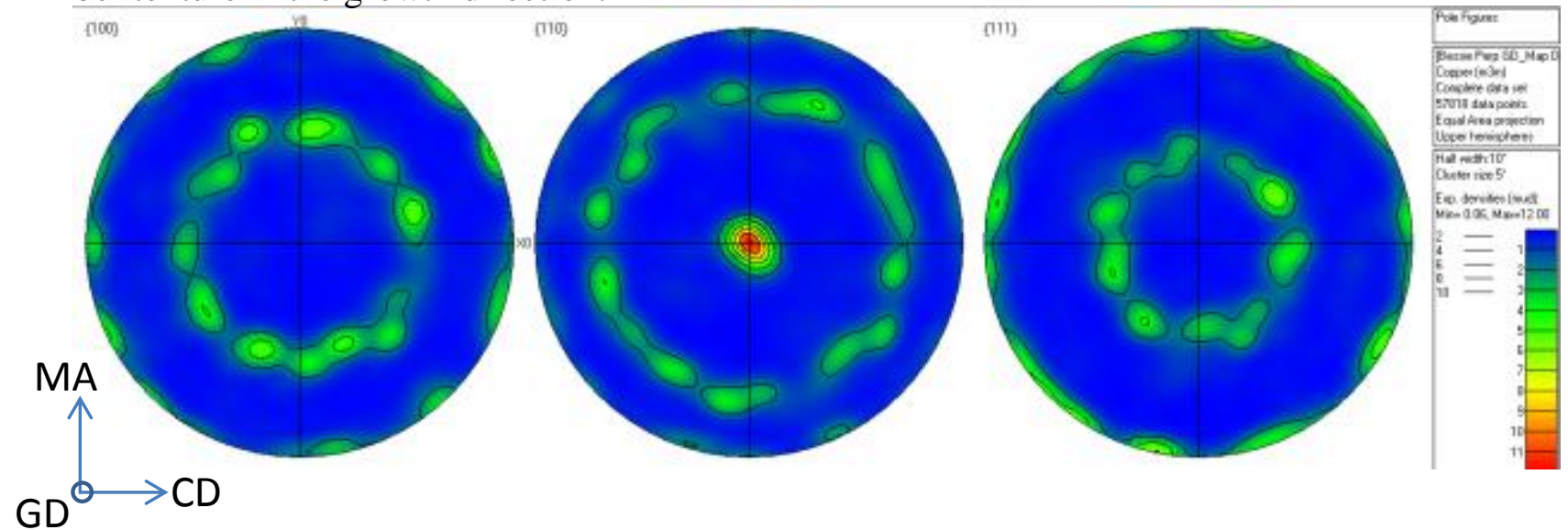

Figure 3.11 Pole Figures from EBSD analysis of prototype copper with test plane perpendicular to growth front. Mandrel Axis (MA) Circumferential Direction (CD). 
The presence of several very large grains shown in Figure 3.10 could be biasing the results which indicate a strong texture is present ${ }^{4}$. Future work will include further EBSD analyses. After a statistically significant number of grain orientation maps are generated, any predominant orientation should be apparent.

\subsubsection{Nodule Analysis}

The formation of nodules has been a continuous issue in some electroplating baths. Figure 3.12 below shows a comparison of two electroplating baths from the Majorana Temporary Clean Room (TCR) located at the 4850' level at Sanford Underground Lab (SUL) in Lead, South Dakota. The figure located on the left shows a normal electroplate while the figure on the right shows nodule formation. From research bath experimentation, filtration has been linked to a significant reduction in nodule formation, for these reasons it was hypothesized that the nodule formation was due to particulate present in the bath solution.

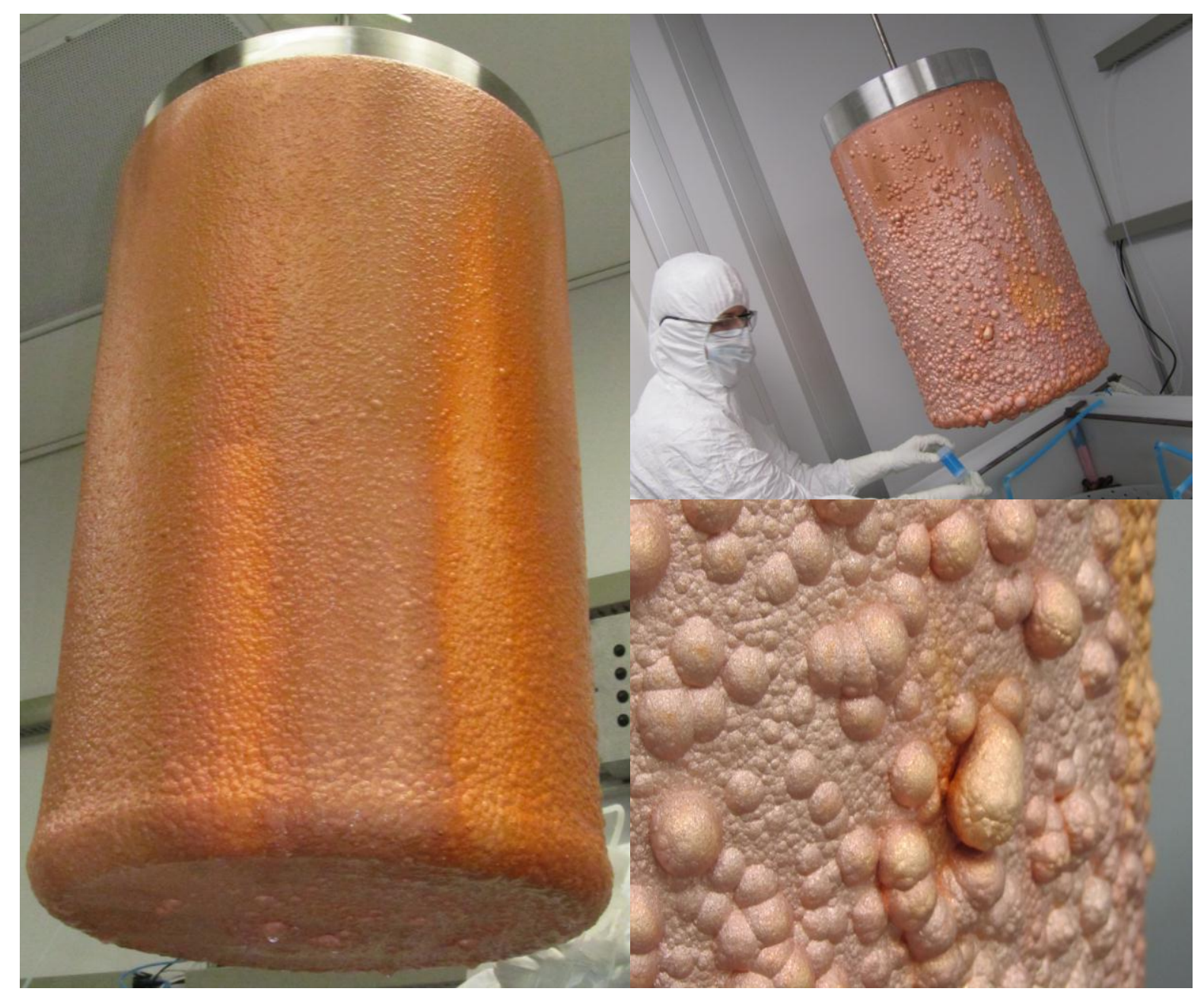

Figure 3.12 Nodular growth seen in TCR Bath \#1. 
Recently, EBSD analysis has been performed on a thin electroplated sample which produced one large nodule. The nodule was sectioned and EBSD was utilized to evaluate the grain structure, Figure 3.13.

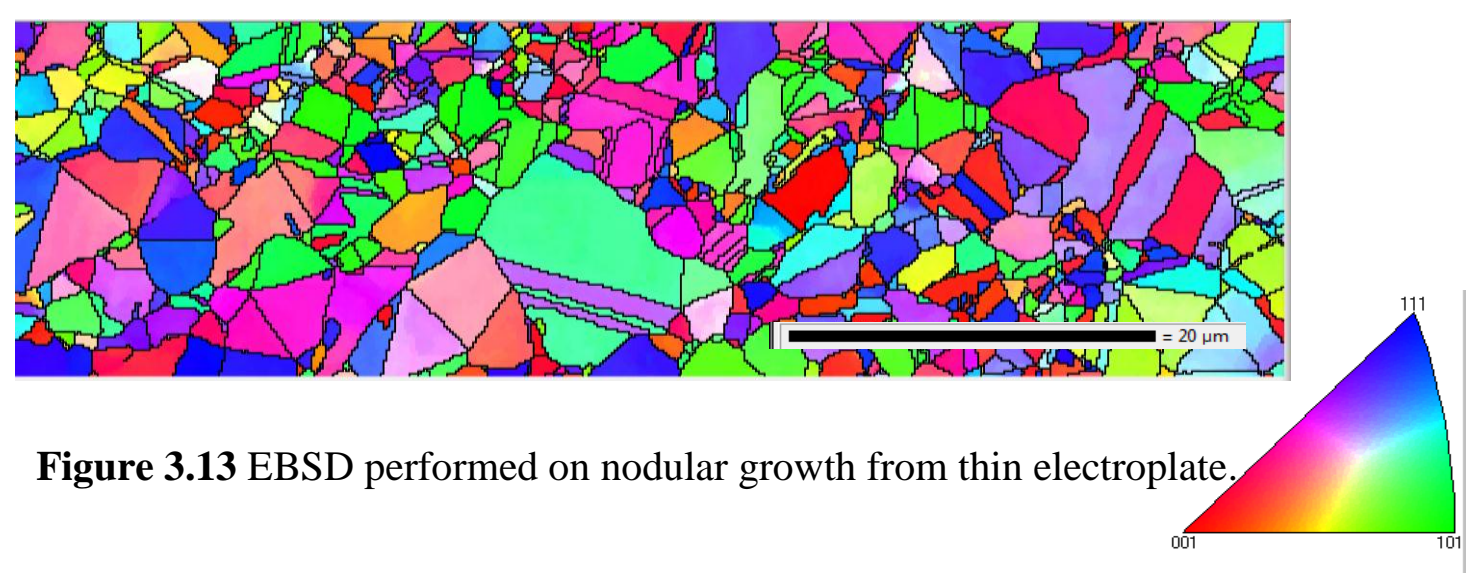

Results from SEM analyses show the nodular copper to be composed of ultra-fine grained material. Magnification of the map had to be increased to well above the scale shown in Figure 3.10 so that individual grains could be distinguished. The structure of an electroplate is determined by the substrate surface, composition of the plating solution, and electrodeposition parameters. ${ }^{11}$ However, in the case where nodules form, many of these variables are held constant and the surrounding copper material is free of these defects. Frequently, in solidification of metals, a very fine grained layer is produced in the presence of heterogeneous nucleation sites. Evidence of this for electroplated material is shown in Figure 3.9 where a fine grained layer of electroplated copper is present along the mandrel surface. Additionally, foreign materials can exert a dominating influence on the structure of electrodeposits even if they are codeposited in very small concentrations. ${ }^{11}$ For these reasons, it is believed that the nodule formation occurs as a result of entrained particulate. Future work on cross sectioning should be performed throughout the nodule thickness in an effort to identify a potential initiation site. 


\section{Summary}

To this point, hardness testing has not been shown to be an appropriate replacement for tensile testing. This is due to the fact that the measured yield strength differs by nearly a factor of two when compared to the predicted value from the Tabor relation. Further characterization of the copper could allow for data correction of hardness information, eliminating the need for future tensile testing. This will be dictated by the consistency of the Majorana copper which is currently being grown.

Results have indicated the PNNL electroformed copper is capable of withstanding the engineering design requirements, as material from this prototype exceeded the design criteria of $7 \mathrm{ksi}$ by almost a factor of two. However, further testing is necessary to understand the deformation and failure modes exhibited, as there is sufficient information to support some degree of anisotropy is present in the electroplated copper.

Future work will include performing EBSD analysis across larger sample areas and from different locations on the mandrel surface including nodules. Additionally, machining and testing small tensile specimens from samples taken perpendicular to the growth front should also be investigated. If strong texture relationships are identified, heat treatment studies and characterization work on heat treated copper could become necessary to fully recrystallize the structure present. 


\section{References}

1 J.R. Davis, Copper and Copper Alloys (Materials Park, OH: ASM International Handbook Committee, 2001).

2 A. Seifert E.W. Hoppe, C.E. Aalseth, P.P. Bachelor, A.R. Day, D.J. Edwards, T.W. Hossbach, K.E. Litke, J.I.McIntyre, H.S. Miley, S.M. Schulte, J.E. Smart, G.A. Warren, 'Cleaning and Passivation of Copper Surfaces to Remove Surface Radioactivity and Prevent Oxide Formation', Elsevier Science (2001), 1-4.

3 F.T. Avignone III; S.R. Elliott; J. Engle, 'Double Beta Decay, Majorana Neutrinos, and Neutrino Mass', Reviews of Modern Physics, 80 (2008).

$4 \quad$ O.; Randle Engler, V., Introduction to Texture Analysis: Macrotexture, Microtexture and Orientation Mapping. 2 ednCRC Press, 2009).

5 V. E. Guiseppe, C. E. Aalseth, M. Akashi-Ronquest, M. Amman, J. F. Amsbaugh, F. T. Avignone, H. O. Back, A. S. Barabash, P. Barbeau, J. R. Beene, M. Bergevin, F. E. Bertrand, M. Boswell, V. Brudanin, W. Bugg, T. H. Burritt, Y. D. Chan, T. V. Cianciolo, J. Collar, R. Creswick, M. Cromaz, J. A. Detwiler, P. J. Doe, J. A. Dunmore, Yu Efremenko, V. Egorov, H. Ejiri, S. R. Elliott, J. Ely, J. Esterline, H. Farach, T. Farmer, J. Fast, P. Finnerty, B. Fujikawa, V. M. Gehman, C. Greenberg, K. Gusey, A. L. Hallin, R. Hazama, R. Henning, A. Hime, E. Hoppe, T. Hossbach, M. A. Howe, D. Hurley, B. Hyronimus, R. A. Johnson, K. J. Keeter, M. Keillor, C. Keller, J. Kephart, M. Kidd, O. Kochetov, S. I. Konovalov, R. T. Kouzes, K. T. Lesko, L. Leviner, P. Luke, A. B. McDonald, S. MacMullin, M. G. Marino, D. M. Mei, H. S. Miley, A. W. Myers, M. Nomachi, B. Odom, J. Orrell, A. W. P. Poon, G. Prior, D. C. Radford, J. H. Reeves, K. Rielage, N. Riley, R. G. H. Robertson, L. Rodriguez, K. P. Rykaczewski, A. G. Schubert, T. Shima, M. Shirchenko, J. Strain, R. Thompson, V. Timkin, W. Tornow, C. Tull, T. D. Van Weche, I. Vanyushin, R. L. Varner, K. Vetter, R. Warner, J. F. Wilkerson, J. M. Wouters, E. Yakushev, A. R. Young, C. H. Yu, V. Yumatov, and C. Zhang, 'The Majorana Neutrinoless Double-Beta Decay Experiment', in Nuclear Science Symposium Conference Record, 2008. NSS '08. IEEE, 2008), pp. 1793-98. K.L. Johnson, Contact Mechanics (Cambridge, UK: Cambridge University Press, 1985). Martin Keillor, Craig Aalseth, Anthony Day, James Fast, Eric Hoppe, Brian Hyronimus, Todd Hossbach, Harry Miley, Allen Seifert, and Glen Warren, 'Design and Construction of an Ultra-Low-Background 14-Crystal Germanium Array for High Efficiency and Coincidence Measurements', Journal of Radioanalytical and Nuclear Chemistry, 282 (2009), 703-08.

8 D. S. Leonard, P. Grinberg, P. Weber, E. Baussan, Z. Djurcic, G. Keefer, A. Piepke, A. Pocar, J. L. Vuilleumier, J. M. Vuilleumier, D. Akimov, A. Bellerive, M. Bowcock, M. Breidenbach, A. Burenkov, R. Conley, W. Craddock, M. Danilov, R. Devoe, M. Dixit, A. Dolgolenko, I. Ekchtout, W. Fairbank, J. Farine, P. Fierlinger, B. Flatt, G. Gratta, M. Green, C. Hall, K. Hall, D. Hallman, C. Hargrove, R. Herbst, J. Hodgson, S. Jeng, S. Kolkowitz, A. Kovalenko, D. Kovalenko, F. LePort, D. Mackay, M. Moe, M. M. Diez, R. Neilson, A. Odian, K. O'Sullivan, L. Ounalli, C. Y. Prescott, P. C. Rowson, D. Schenker, D. Sinclair, K. Skarpaas, G. Smirnov, V. Stekhanov, V. Strickland, C. Virtue, K. Wamba, and J. Wodin, 'Systematic Study of Trace Radioactive Impurities in Candidate 
Construction Materials for Exo-200', Nuclear Instruments \& Methods in Physics Research Section a-Accelerators Spectrometers Detectors and Associated Equipment, 591 (2008), 490-509.

9 Harry S. Miley, Craig E. Aalseth, Anthony R. Day, Orville T. Farmer, Jim E. Fast, Eric W. Hoppe, Todd W. Hossbach, Kevin E. Litke, Justin I. McIntyre, Erin A. Miller, Allen Seifert, and Glen A. Warren, The Chemistry of Ultra-Radiopure Materials, 2007), $\mathrm{p}$. Medium: ED; Size: PDFN.

10 D. Tabor, The Hardness of MetalsOxford University Press, 1951), p. 175.

11 R Weil, 'The Structures of Electrodeposits and the Properties That Depend on Them', Annual Review of Materials Science, 19 (1989), 165-82. 


\section{Acknowledgement}

The authors would like to thank the Majorana Collaboration for their contributions and the Department of Energy Office of Nuclear Physics for financial support. 


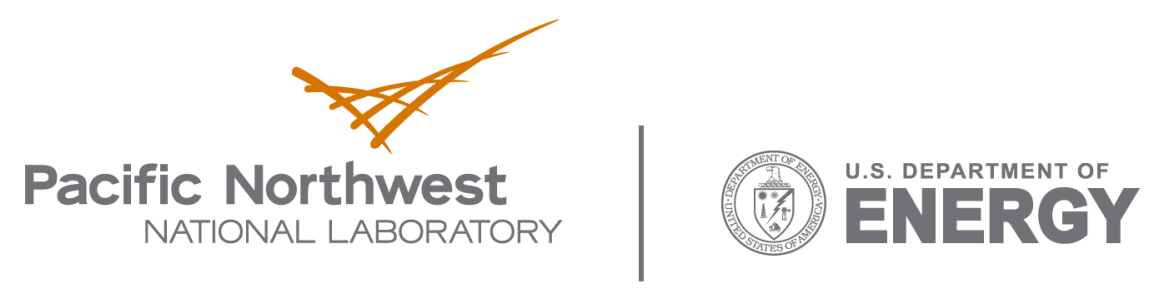

902 Battelle Boulevard

P.O. Box 999

Richland, WA 99352

1-888-375-PNNL (7665)

www.pnl.gov 